\title{
Impact of reducing dosing frequency on adherence to oral therapies: a literature review and meta-analysis
}

This article was published in the following Dove Press journal:

Patient Preference and Adherence

2I May 2013

Number of times this article has been viewed

\author{
Kunal Srivastava' \\ Anamika Arora' \\ Aditi Kataria' \\ Joseph C Cappelleri² \\ Alesia Sadosky ${ }^{3}$ \\ Andrew M Peterson ${ }^{4}$ \\ 'HERON Health PVT, Chandigarh, \\ India; ${ }^{2}$ Pfizer Inc, Statistics, Groton, \\ CT, USA; ${ }^{3}$ Pfizer Inc Global Health \\ Economics and Outcomes Research, \\ New York, NY, USA; ${ }^{4}$ Mayes \\ College of Healthcare Business and \\ Policy, University of the Sciences, \\ Philadelphia, PA, USA
}

Objectives: To assess the impact of reduced frequency of oral therapies from multiple-dosing schedules to a once-daily (OD) dosing schedule on adherence, compliance, persistence, and associated economic impact.

Methods: A meta-analysis was performed based on relevant articles identified from a comprehensive literature review using MEDLINE ${ }^{\circledR}$ and Embase ${ }^{\circledR}$. The review included studies assessing adherence with OD, twice-daily (BID), thrice-daily (TID), and four-times daily (QID) dosing schedules and costs associated with optimal/suboptimal adherence among patients with acute and chronic diseases. Effect estimates across studies were pooled and analyzed using the DerSimonian and Laird random-effect model.

Results: Forty-three studies met inclusion criteria, and meta-analyzable data were available from 13 studies. The overall results indicated that OD schedules were associated with higher adherence rates (odds ratio [OR] 3.07, 95\% confidence interval [CI] 1.80-5.23; $P<0.001$ for OD versus $>$ OD dosing) and compliance rates (OR 3.50, 95\% CI 1.73-7.08; $P<0.001$ for OD versus $>$ OD dosing); persistence rates showed the same direction but were not statistically significant (OR 1.43, 95\% CI 0.62-3.29; $P=0.405$ for OD versus BID dosing). Results for each of the conditions were consistent with those observed overall with respect to showing the benefits of less frequent dosing. From a health economic perspective, higher adherence rates with OD relative to multiple dosing in a number of conditions were consistently associated with corresponding lower costs of health care resources utilization.

Conclusion: Current meta-analyses suggested that across acute and chronic disease states, reducing dosage frequency from multiple dosing to OD dosing may improve adherence to therapies among patients. Improving adherence may result in subsequent decreases in health care costs.

Keywords: compliance, dosage frequency, persistence, random-effect meta-analyses

\section{Introduction}

Worldwide public health efforts to address a variety of chronic conditions are being undermined by an alarmingly low adherence to therapies. ${ }^{1}$ Nonadherence is a serious problem in patients on long-term treatment, accounting for up to $50 \%$ of cases where drugs fall short of their therapeutic goals. ${ }^{2-4}$ For nonadherent patients, the benefits of extended duration of treatment may not be sufficiently apparent. ${ }^{2,3}$ Adherence problems are prevalent where self-administration of treatment is required, including acute and chronic illnesses such as hypertension, ${ }^{5}$ depression, ${ }^{6}$ diabetes, ${ }^{7}$ HIV/AIDS,${ }^{8}$ transplant, ${ }^{9}$ and cardiovascular $(\mathrm{CV})$ disorders. ${ }^{10}$

Nonadherence to treatment is a difficult issue to evaluate due to inconsistent definitions and measurement methodologies. ${ }^{11}$ Standard definitions of adherence,
Correspondence: Alesia Sadosky

Pfizer Inc, 235 East 42nd Street,

New York, NY 10017, USA

$\mathrm{Tel}+\mathrm{I} 212733949 \mid$

Fax + I $64644 \mid 4757$

Email alesia.sadosky@pfizer.com 
compliance, and persistence were developed by the International Society for Pharmacoeconomics and Outcomes Research (ISPOR) Medication Compliance and Persistence Work Group. ${ }^{12}$ According to the group, medication compliance (synonym: adherence) refers to conforming to the recommendations made by a provider with respect to timing, dosing, and frequency of medication taking. ${ }^{12}$ Medication persistence refers to conforming to a recommendation of continuing treatment for the prescribed length of time. ${ }^{12}$ A wide variety of factors contribute to nonadherence, ${ }^{13,14}$ including drug regimen complexity as a major contributing factor. ${ }^{15}$

Until 2006, published reviews and meta-analyses focusing on adherence, compliance, and persistence demonstrated that decreasing the number of doses taken daily provides benefits in terms of medication-taking behaviour. ${ }^{15-19}$ These reviews and meta-analyses neither examined observational studies nor assessed the impact on associated costs.

To fill this gap, a comprehensive literature review and meta-analyses were conducted to assess the impact of multiple-daily dosing and once-daily (OD) dosing of oral therapies prescribed in acute and chronic diseases on adherence, compliance, persistence, and health care costs. The authors of the current study would also like to note that subsequent to our analyses and prior to submission for publication, a comprehensive and rigorous meta-analytic study was published that evaluated the relationship between dosing frequency and medication adherence in studies of patients with chronic diseases..$^{20}$ That study, which provides a valuable update of the literature, confirmed the inverse relationship between medication adherence and dosing frequency, with once daily dosing shown to be associated with the greatest adherence. However, similar to other studies, there was no evaluation of the impact of dosing frequency on costs, and neither did that study stratify the analyses by disease states.

\section{Materials and methods}

The original objective was to compare adherence to OD dosing regimen with that of multiple-dosing regimens in patients with chronic pain but, because of the lack of published evidence in this disease area, the investigation was expanded by not including a term that would have limited the search to chronic pain. This comprehensive literature review was conducted and reported in accordance with the Preferred Reporting Items for Systematic Reviews and Meta-analyses (PRISMA) guidelines. ${ }^{21}$

\section{Study eligibility criteria}

This review included comparative studies published in English and assessed adherence/compliance/persistence with OD, twice-daily (BID), three-times daily (TID), or four-times daily (QID) dosing, including associated costs among patients with acute and chronic diseases. There was no restriction on the treatments assessed in the study other than that they were orally administered.

\section{Data source and evidence synthesis}

The search was conducted in MEDLINE ${ }^{\circledR}$ (including MEDLINE ${ }^{\circledR}$ In-Process) and Embase ${ }^{\circledR}$ up to September 16, 2011. All retrieved studies were screened, and only those meeting predefined eligibility criteria (Appendix) were included in the review.

Initial screening of the retrieved citations was conducted independently by two reviewers on the basis of the title and the abstract. Any discrepancy between the reviewers was reconciled by a third reviewer. The full-text publications of all citations of potential interest were then screened for inclusion by two independent reviewers, with all disagreements reconciled by a third reviewer. Relevant data from all included studies were extracted independently by two reviewers using a predefined extraction grid; any differences were then resolved by a third independent reviewer.

Extracted data included percentage of patients adherent and nonadherent to therapy, medication possession ratio (MPR), and odds ratio (OR) or risk ratio or $\beta$-coefficient to evaluate the association between adherence with different dosing schedules. Costs associated with optimal/suboptimal adherence and quality-adjusted life-years (QALYs) were also extracted. The same type of extraction for adherence was performed for compliance and persistence. Due to variability in definitions of adherence/compliance/persistence across studies, no single definition criteria was used to define these parameters. The studies were classified as evaluating adherence/compliance/persistence based on author definitions in the associated studies for the purpose of quantitative analyses.

\section{Statistical analysis}

Random-effect meta-analyses using the DerSimonian and Laird random-effects model were conducted. ${ }^{22}$ Estimated ORs for the studies were combined using Stata ${ }^{\circledR}$ v11.1. For the purpose of analysis, data for all dosing schedules administered more than OD were pooled under $>$ OD regimen group; $P \leq 0.05$ was considered statistically significant. 
The statistical heterogeneity within each analysis was assessed using the $\mathrm{I}^{2}$ statistic. ${ }^{23}$ Multivariate-adjusted effect estimates were included in the meta-analysis; however, when multivariate effect estimates were not available, unadjusted ORs were computed from the treatment distributions for those with and without the event of interest reported in the published articles. A linear meta-regression considering random-effect modeling was performed using Stata ${ }^{\circledR}$ v11.1 (Stata Statistical Software: Release 12. StataCorp LP, College Station, TX, USA) to explore the effect on adherence, compliance, or persistence with respect to different dosing schedules. ${ }^{24}$

\section{Results}

The search terms and strategy are shown in Table 1, and the schematic selection process of studies from the identified records is presented in Figure 1. Forty-three studies (44 publications) fulfilled the inclusion criteria and provided the basis for this review, encompassing a variety of acute and chronic conditions in addition to pain. The characteristics of these studies including the outcome evaluated (eg, adherence, compliance, and/or persistence) are summarized in Table 2. Of these 43 studies, 13 were amenable to conducting random-effect meta-analyses. Studies with non-meta-analyzable data were discussed descriptively.

\section{Overall associations}

\section{Overall association of adherence with dosing}

\section{frequencies}

Random-effects meta-analysis was conducted on pooled ORs derived from various disease conditions to compare OD versus BID, BID versus TID, and OD versus $>$ OD regimens in terms of adherence. OD dosing was associated with significantly better adherence rates compared with BID (seven studies, OR 2.20, 95\% confidence interval [CI] $1.09-4.41, P=0.027, \mathrm{I}^{2}=95.5 \%$ ). No significant difference was observed between BID and TID dosing (three studies, OR $1.88,95 \%$ CI $0.85-4.13, P=0.118, \mathrm{I}^{2}=61.9 \%$ ).
OD dosing showed significantly greater adherence rates compared with $>$ OD dosing (ten studies, OR 3.07, 95\% CI $1.80-5.23, P<0.001, \mathrm{I}^{2}=91.3 \%$ ) (Figure 2).

A random-effects model regression plot using 13 point estimates (ten studies) for adherence using OD dosing as reference showed that an increase by one dose daily (eg, OD to BID) resulted in a twofold reduction in the odds of adherence (OR 2.03, 95\% CI 1.84-7.46).

\section{Overall association of compliance with dosing frequencies}

Random-effects meta-analysis of pooled ORs across disease conditions demonstrated OD dosing had significantly better compliance than $>$ OD dosing (six studies, OR 3.50, 95\% CI 1.73-7.08, $P<0.001, \mathrm{I}^{2}=69.0 \%$ ) (Figure 3). A similar trend was observed for OD versus BID dosing (six studies, OR 4.08, 95\% CI 1.68-9.91, $P=0.002, \mathrm{I}^{2}=73.4 \%$ ).

\section{Association of persistence with dosing frequencies}

Pooling the data across disease conditions, random-effects meta-analyses illustrated high persistence rates with OD compared with BID dosing (three studies, OR 1.43, 95\% CI $0.62-3.29, P=0.405, \mathrm{I}^{2}=96.9 \%$ ) (Figure 4). However, due to considerable heterogeneity between studies, the results should be interpreted with caution.

\section{Sensitivity analysis}

Sensitivity analyses conducted by study design indicated no differential effects compared with that of the results indicated by the overall meta-analysis. A higher magnitude of effect was observed with OD compared with the other dosing regimens. For prospective studies, ${ }^{25-34}$ adherence of OD versus $>$ OD resulted in an OR of $7.11(95 \%$ CI 1.98-25.59, $P=0.003)$ and compliance of $\mathrm{OD}$ versus $>\mathrm{OD}$ had an $\mathrm{OR}$ of $3.61(95 \%$ CI $1.68-7.78, P=0.001)$. In the retrospective studies, ${ }^{6,7,35-37}$ adherence of OD versus $>$ OD showed an OR

Table I Search terms and initial strategy for identifying relevant studies

\begin{tabular}{|c|c|}
\hline $\begin{array}{l}\text { Search } \\
\text { number }\end{array}$ & Search strings \\
\hline \multirow[t]{2}{*}{ I } & (once OR twice OR thrice OR one OR two OR three) NEAR/I (daily* OR per*day) OR ‘OD’:ab,ti OR \\
\hline & ‘BID’:ab,ti OR ‘TID’:ab,ti OR ‘QID’:ab,ti \\
\hline \multirow[t]{4}{*}{2} & adhere*:ab,ti OR nonadhere*:ab,ti OR (non NEAR/I adhere*):ab,ti OR complian*:ab,ti OR noncomplian*:ab,ti OR \\
\hline & (non NEAR/I complian*):ab,ti OR ‘medication possession’:ab,ti OR mpr:ab,ti OR ‘persistence’:ab,ti OR (non NEAR/I \\
\hline & persist*):ab,ti OR nonpersisten*:ab,ti OR 'medication possession ratio' OR 'treatment refusal' OR 'medication \\
\hline & compliance'/exp OR medication NEAR/I complian* OR medication NEAR/I persisten* OR medication NEAR/I adhere* \\
\hline 3 & patient NEAR/I (monitoring OR care OR counselling) \\
\hline 4 & \#2 OR \#3 \\
\hline 5 & \#I AND \#4 \\
\hline
\end{tabular}




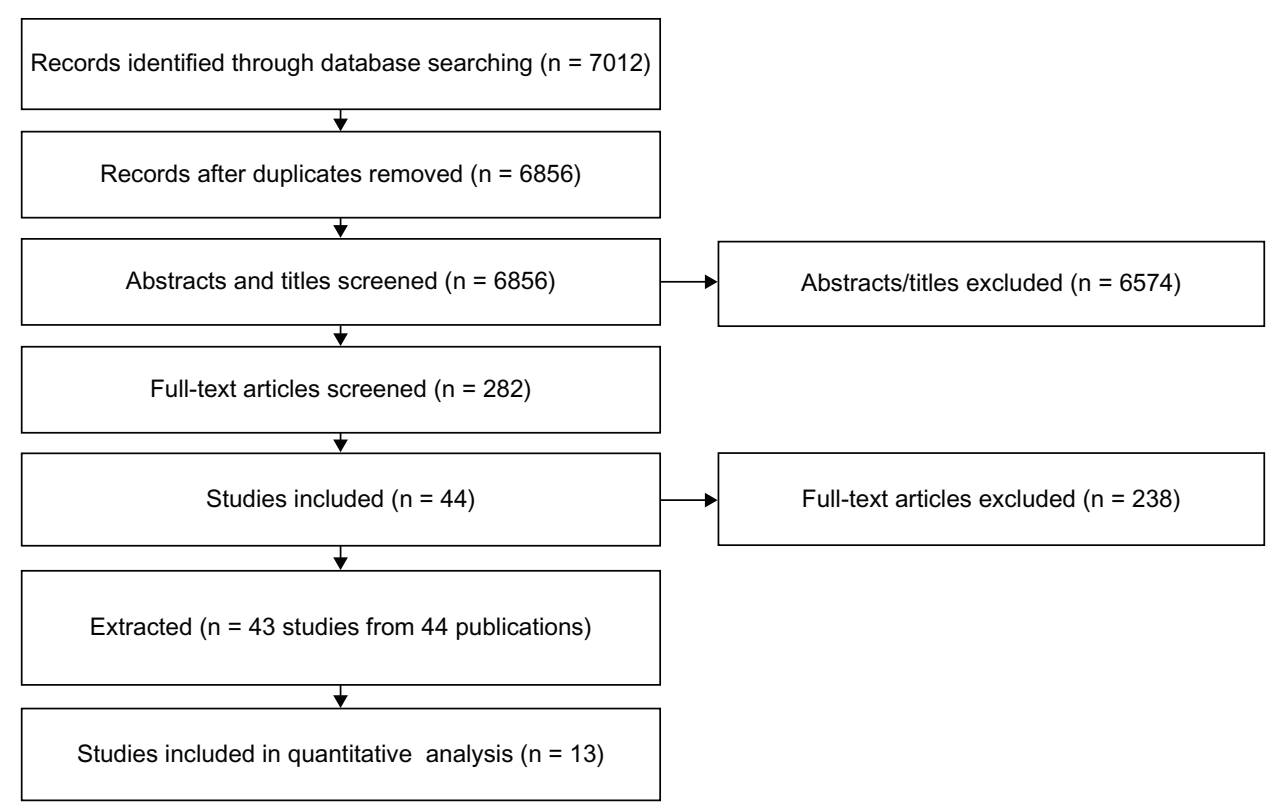

Figure I Search terms and strategy for identifying relevant studies.

of 2.37 (95\% CI 1.98-2.83, $P<0.001$ ), and persistence of OD versus BID resulted in an OR of 1.43 (95\% CI 0.62-3.27, $P=0.401)$. Adherence of OD versus $>$ OD in cross-sectional studies $^{37-39}$ resulted in an OR of 2.39 (95\% CI $0.60-9.49$, $P=0.217){ }^{38-40}$

Combining the pooled estimates (Z-statistic) between different study designs (cross-sectional, prospective, retrospective, randomized controlled trial [RCT], non-RCT) and analysis types (multivariate, univariate) to examine adherence/persistence/compliance rates for OD dosing versus $>$ OD dosing across disease conditions did not show evidence of bias in results.

\section{Publication bias}

Funnel plots showed no marked asymmetry and Egger's tests demonstrated statistically nonsignificant differences; $P=0.80$ for compliance of OD versus $>$ OD in prospective studies and $P=0.24$ for adherence of $\mathrm{OD}$ versus $>\mathrm{OD}$ in cross-sectional studies. ${ }^{41,42}$ However, visual inspection of the funnel and Egger's plots indicated that publication bias or other biases cannot be completely ruled out, and such bias might have been introduced in the process of locating, selecting, and combining studies.

\section{Disease-specific association of adherence with dosing frequencies Cardiovascular disorders}

Thirteen studies evaluated the association of adherence/ persistence/compliance with different dosing schedules among CV disorders including hypertension, ${ }^{29,30,34,40,43-45}$ angina pectoris,${ }^{46,47}$ atrial fibrillation, ${ }^{10}$ heart transplant, ${ }^{48}$ and acute coronary syndrome (Table 3 ). ${ }^{37}$

Random-effect meta-analysis for compliance indicated that OD dosing was associated with significantly higher compliance rates compared with BID dosing in three studies (OR 2.42, 95\% CI 1.33-4.40, $P=0.004, \mathrm{I}^{2}=0 \%$ ) (Table 3). ${ }^{29,30,34}$ Patients with OD dosing were approximately 2.5 times as likely to comply with therapy than BID dosing of antihypertensive medications. Similarly, random-effect meta-analysis for persistence to medications for acute coronary syndrome showed no difference between OD and BID dosing (OR 0.85, 95\% CI $0.65-1.11, P=0.235, \mathrm{I}^{2}=$ not applicable) ${ }^{37}$

In contrast to the above results, Turki and Sulaiman ${ }^{40}$ showed significantly greater adherence with multiple doses (BID and $>$ BID) of antihypertensive medications compared with OD dosing $(P<0.001)$. All other empirical studies on $\mathrm{CV}$ disorders (atrial fibrillation, heart transplant, and angina) demonstrated an improvement in adherence, compliance, and persistence to OD dosing compared with BID dosing. ${ }^{10,47-49}$

Brown et $\mathrm{a}^{46}$ developed a decision-analytic model to compare costs of treating exercise-induced angina with OD versus BID isosorbide mononitrate. Fewer medical resources were consumed by patients treated with OD versus BID dosing. The economic data suggested that, even though the per-tablet cost of OD was more than BID, the annual patient management costs were nearly the same for both regimens due to better compliance with the OD regimen (Table 4). ${ }^{46}$ 


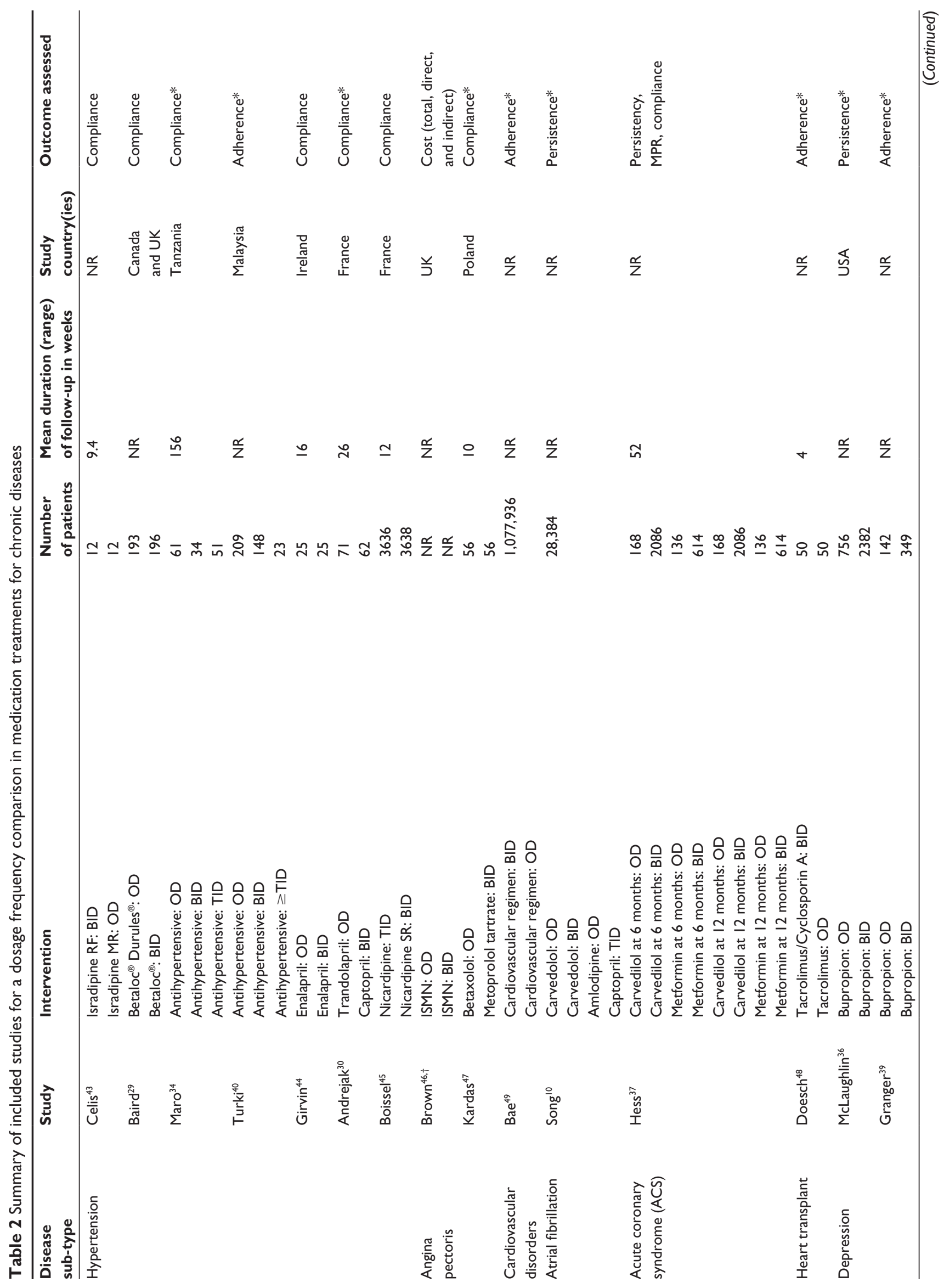




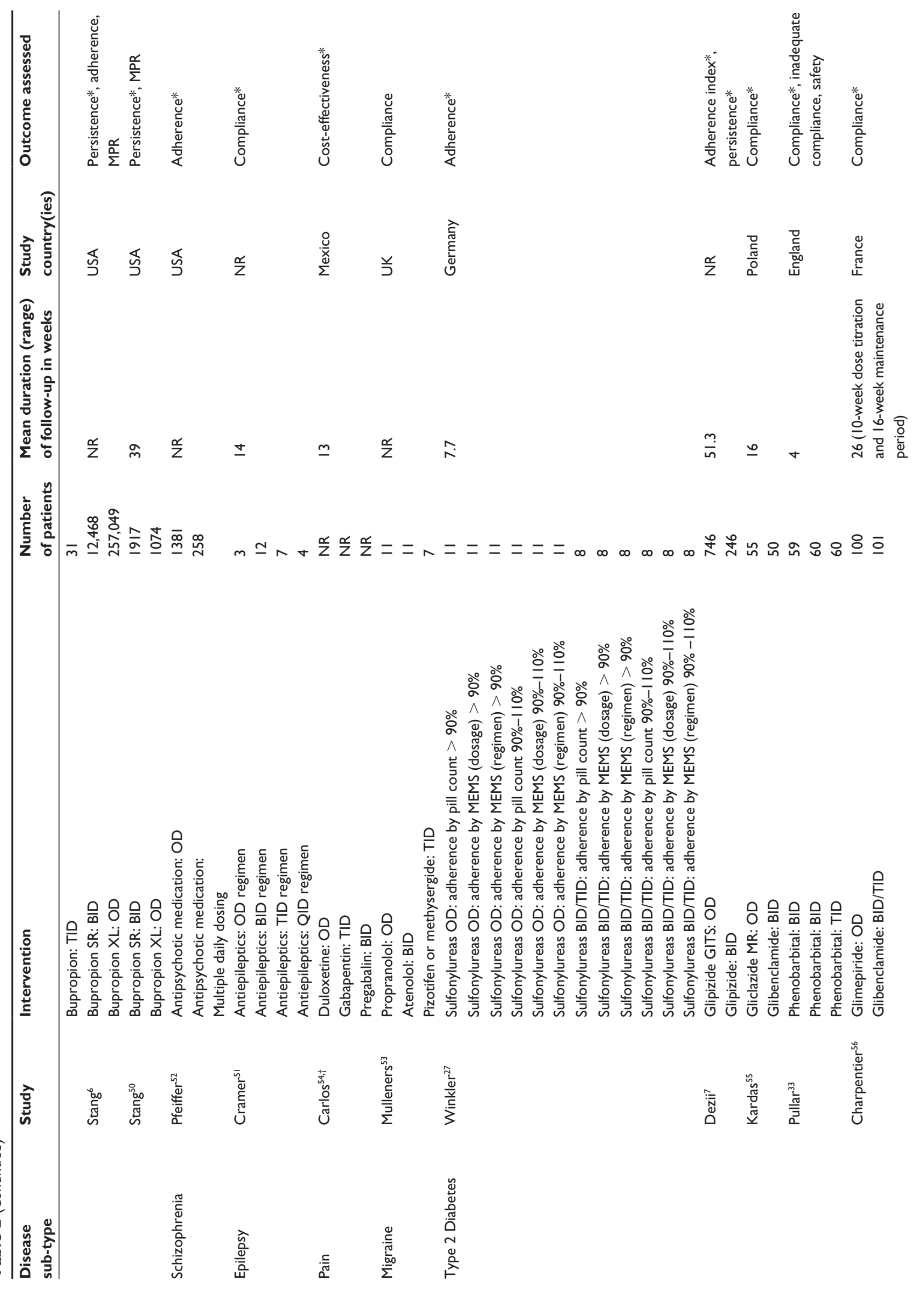




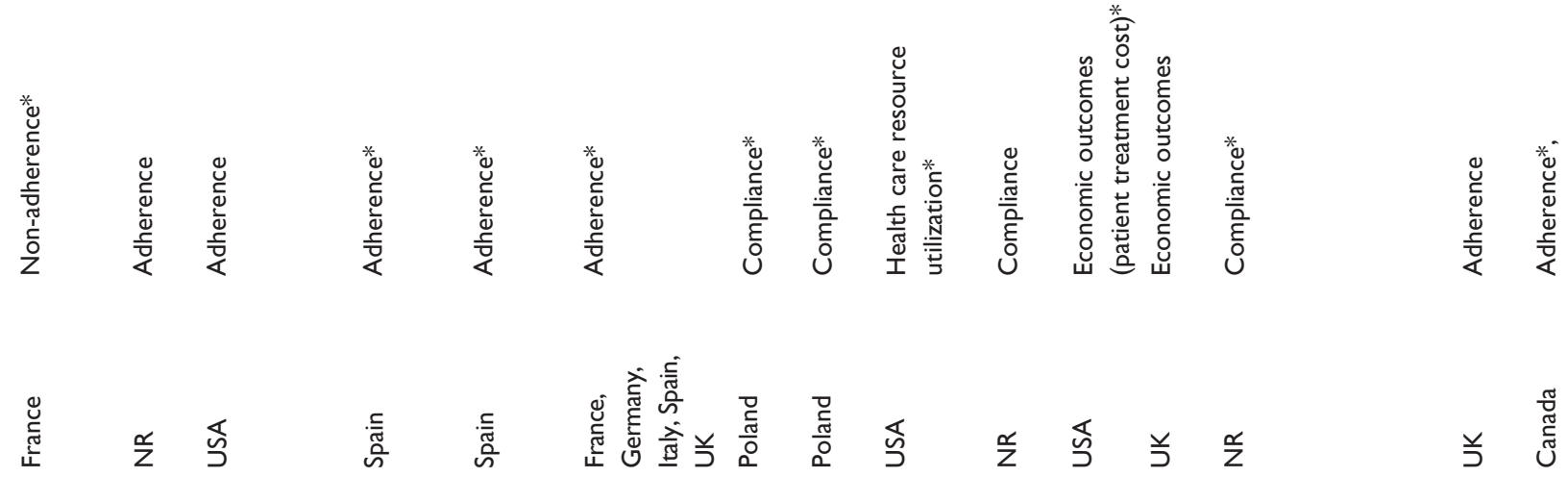

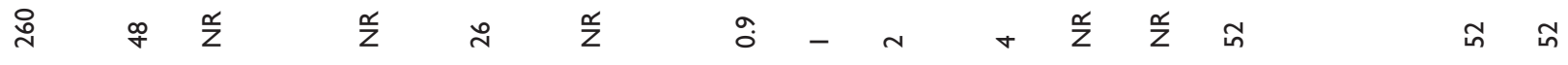

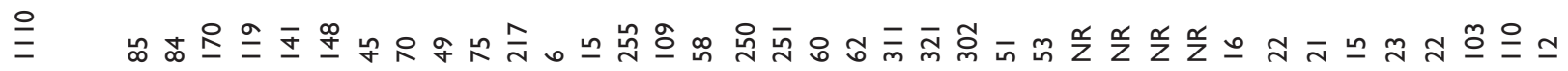

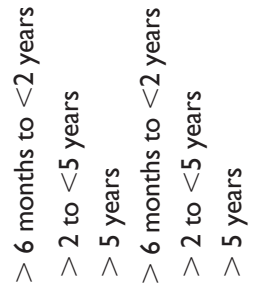

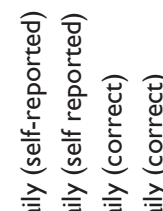

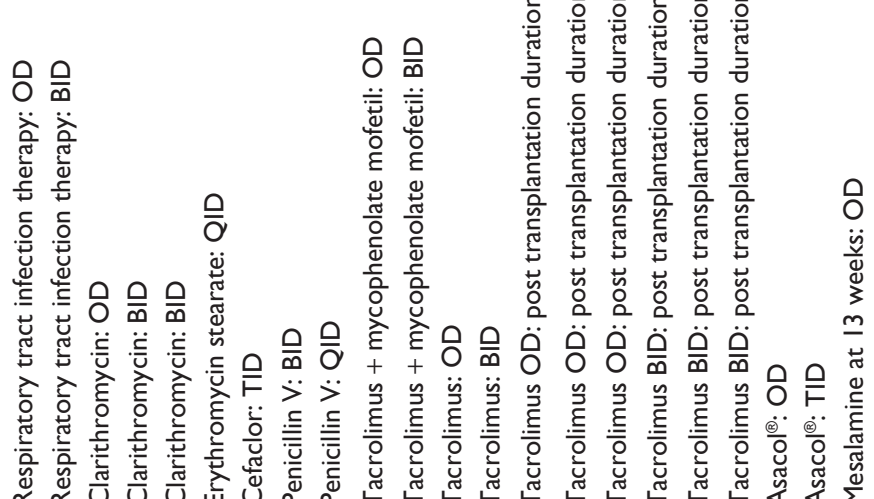

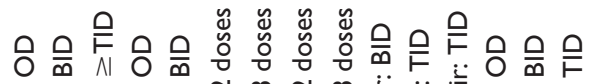

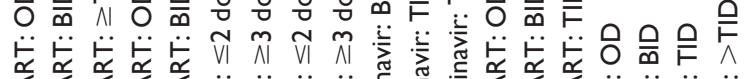

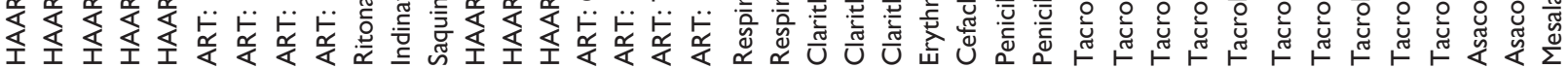

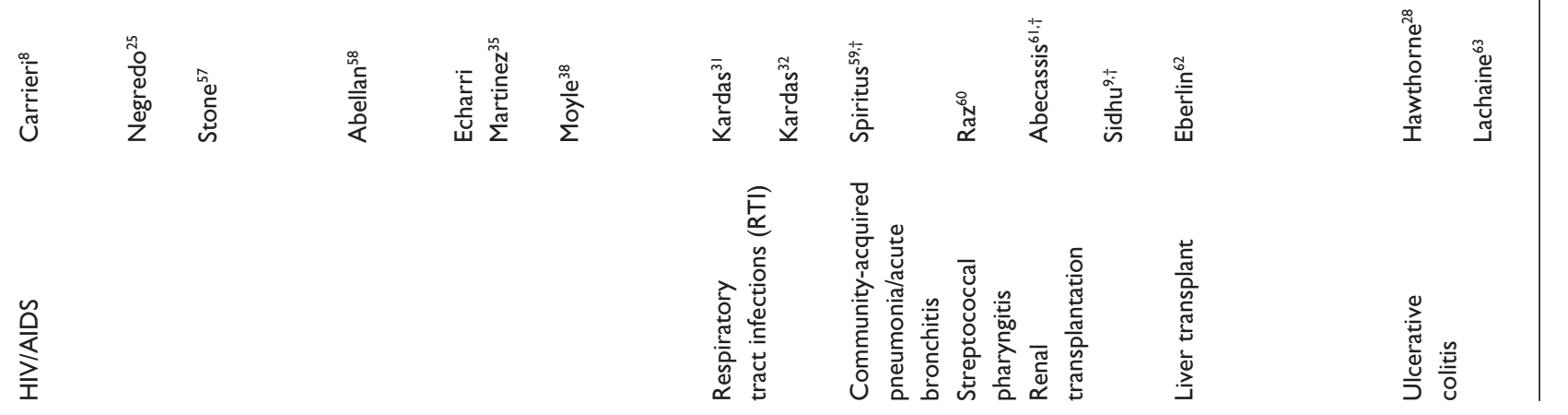




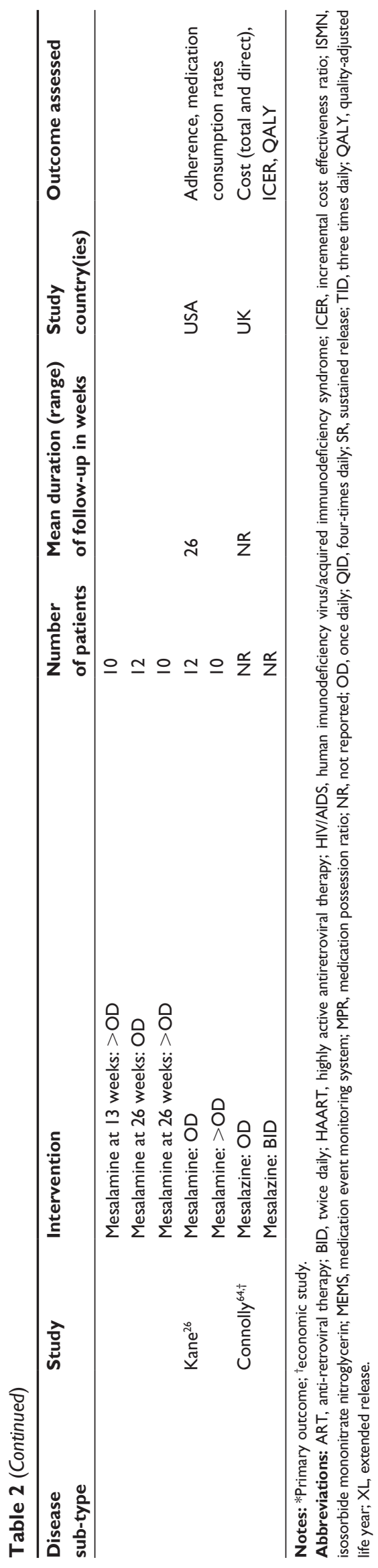

\section{Neurological disorders}

Neurological disorders such as depression, ${ }^{6,36,39,50}$ epilepsy, ${ }^{51}$ and schizophrenia ${ }^{52}$ were studied in six trials. Three studies in patients with depression ${ }^{6,35,38}$ contributed adherence data for meta-analysis (Table 3). Random-effect meta-analysis showed that OD dosing was associated with nearly three times higher adherence compared with BID dosing (OR 3.10, 95\% CI 2.15-4.47, $P<0.001, \mathrm{I}^{2}=82.9 \%$ ).

Pfeiffer et a ${ }^{52}$ demonstrated that a decrease in daily dosing frequency resulted in a small but significant increase in adherence measured using antipsychotic mean MPR change of 0.45 compared with -0.018 for schizophrenic patients without dosing frequency change $(P<0.001)$. Cramer et $\mathrm{al}^{51}$ reported mean compliance rates of $87 \%, 81 \%, 77 \%$, and $39 \%$ with antiepileptics prescribed as OD, BID, TID, and QID regimens, respectively. Overall, results of other empirical studies demonstrated that a decrease in daily dosage frequency was associated with increased adherence, compliance, or persistence (Table 2). ${ }^{6,36,39,50}$

Pain

There was little published evidence on adherence to treatments for pain. Two studies, one of which was observational ${ }^{53}$

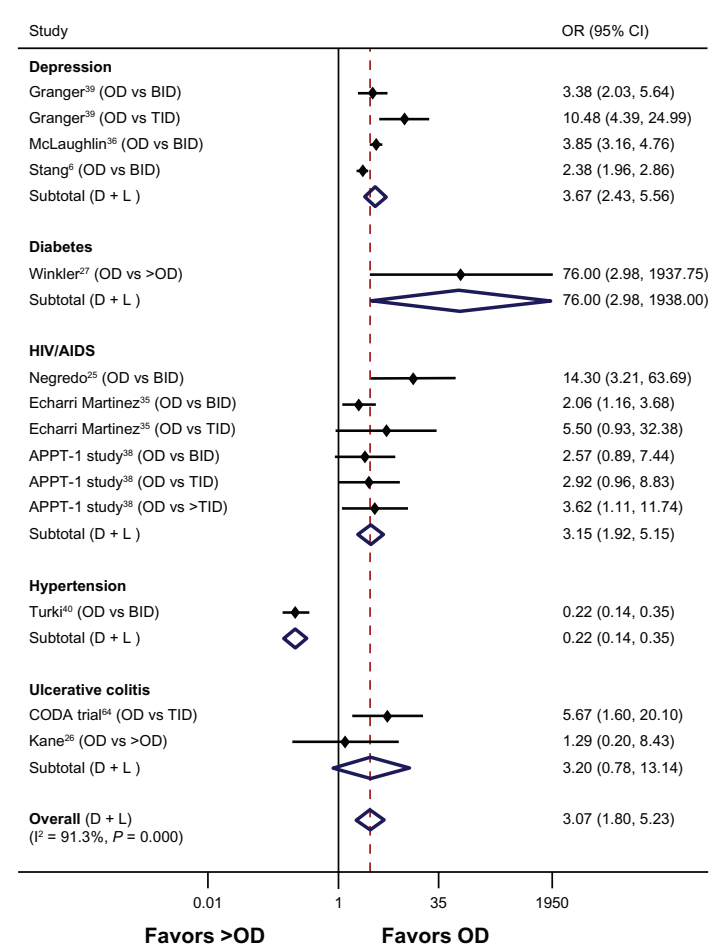

Figure 2 Forest plot of the odds ratios and $95 \% \mathrm{Cls}$ for adherence rates associated with dosing schedules (once daily versus $>$ once daily) of medications in all diseases. Note: The broken line indicates overall effect relative to the comparator.

Abbreviations: BID, twice daily; Cl, confidence interval; D + L, DerSimonian and Laird technique for meta-analysis; OD, once daily; OR, odds ratio; TID, three times daily; vs, versus; $1^{2}$, statistical heterogeneity. 


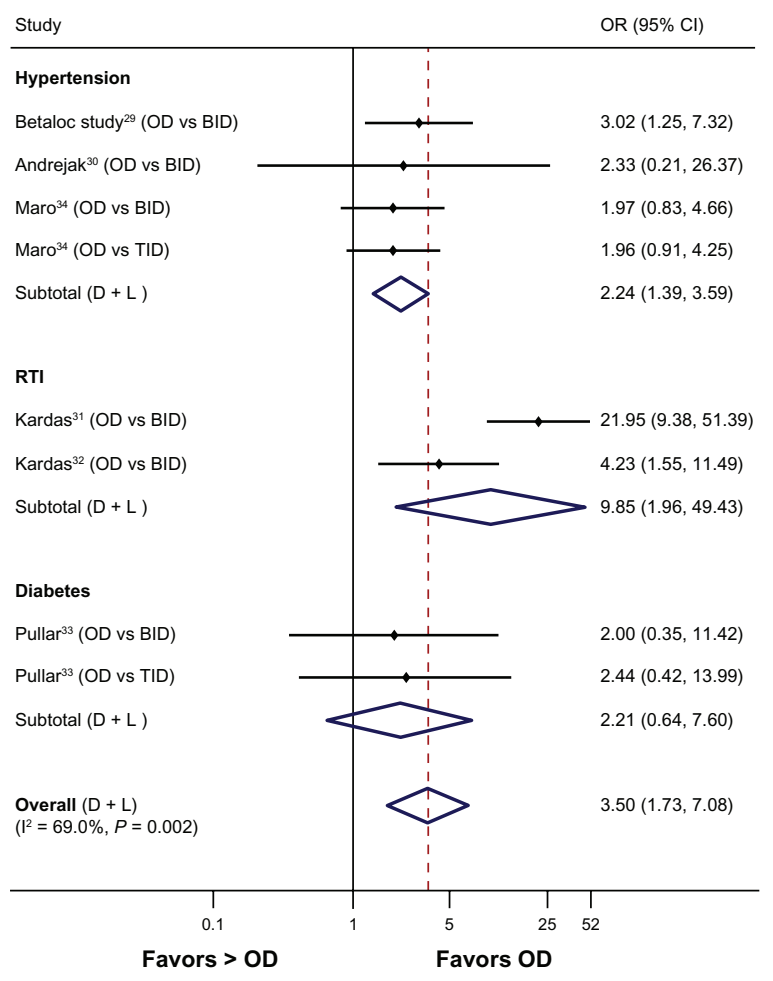

Figure 3 Forest plot of the odds ratios and $95 \%$ Cls for compliance rates associated with dosing schedules (once daily versus $>$ once daily) of medications in all diseases. Note: The broken line indicates overall effect relative to the comparator.

Abbreviations: $\mathrm{BID}$, twice daily; $\mathrm{Cl}$, confidence interval; $\mathrm{D}+\mathrm{L}$, DerSimonian and Laird technique for meta-analysis; OD, once daily; RTI, respiratory tract infections; TID, three times daily; vs, versus; OR, odds ratio; $I^{2}$, statistical heterogeneity.

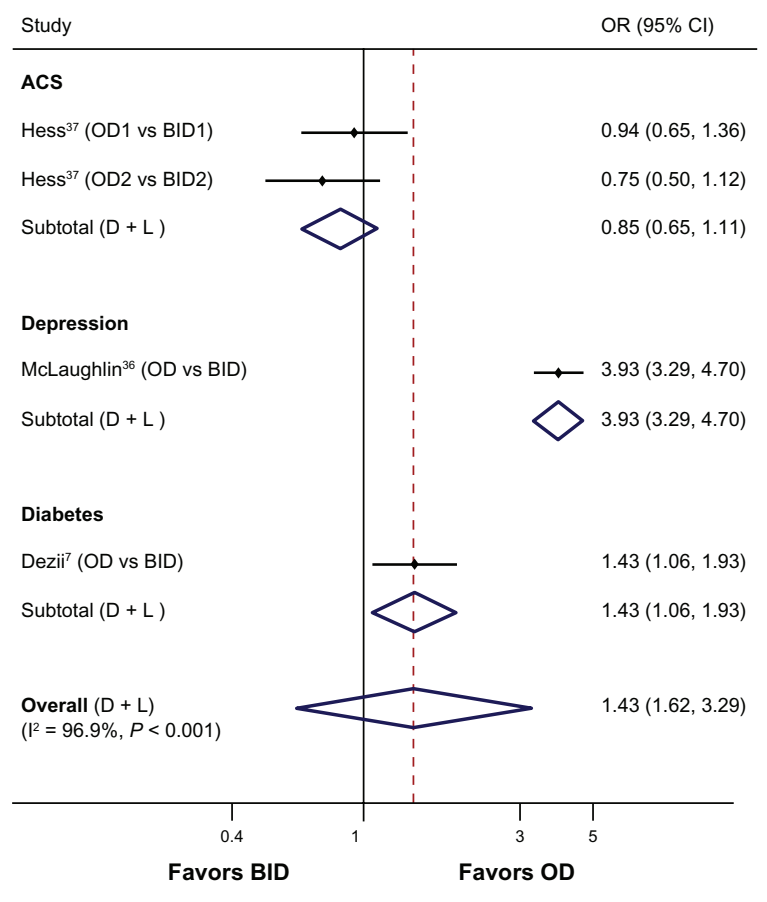

Figure 4 Forest plot of the odds ratios and $95 \% \mathrm{Cls}$ for persistence rates associated with OD versus BID dosing schedules of medications in all diseases.

Note: The broken line indicates overall effect relative to the comparator.

Abbreviations: ACS, acute coronary syndrome; BID, twice daily; $\mathrm{Cl}$, confidence interval; D + L, DerSimonian and Laird technique for meta-analysis; OD, once daily; vs, versus; OR, odds ratio; $I^{2}$, statistical heterogeneity.
Table 3 Random effects meta-analyses for association of adherence/compliance/persistence to dosing schedules of medications in various chronic disorders

\begin{tabular}{|c|c|c|}
\hline Disease & $\begin{array}{l}\text { Dose } \\
\text { comparison }\end{array}$ & $\begin{array}{l}\text { OR }(95 \% \mathrm{Cl}) ; \\
\text { P-value; heterogeneity }\end{array}$ \\
\hline \multicolumn{3}{|l|}{ Adherence } \\
\hline Depression & OD vs BID & $\begin{array}{l}3.10(2.15-4.47) \\
P<0.00 I ; I^{2}=82.9 \%\end{array}$ \\
\hline \multirow[t]{2}{*}{ Ulcerative colitis } & OD vs $>O D$ & $\begin{array}{l}3.20(0.78-13.14) \\
P=0.107 ; I^{2}=39.4 \%\end{array}$ \\
\hline & OD vs BID & $\begin{array}{l}3.48(1.32-9.17) \\
P=0.012 ; I^{2}=64.4 \%\end{array}$ \\
\hline \multirow[t]{2}{*}{ HIVIAIDS } & OD vs TID & $\begin{array}{l}3.48(1.36-8.90) \\
P=0.009 ; I^{2}=0 \%\end{array}$ \\
\hline & BID vs TID & $\begin{array}{l}1.38(0.87-2.17) \\
P=0.167 ;\left.\right|^{2}=0 \%\end{array}$ \\
\hline $\begin{array}{l}\text { Across all the } \\
\text { diseases }\end{array}$ & OD vs BID & $\begin{array}{l}2.20(I .09-4.4 I) \\
P=0.027 ; I^{2}=95.5 \%\end{array}$ \\
\hline $\begin{array}{l}\text { Across all the } \\
\text { diseases }\end{array}$ & BID vs TID & $\begin{array}{l}1.88(0.85-4.13) \\
P=0.1|8 ;|^{2}=61.9 \%\end{array}$ \\
\hline $\begin{array}{l}\text { Across all the } \\
\text { diseases }\end{array}$ & OD vs $>O D$ & $\begin{array}{l}3.07(1.80-5.23) \\
P<0.00 I ; I^{2}=91.3 \%\end{array}$ \\
\hline \multicolumn{3}{|l|}{ Compliance } \\
\hline Hypertension & OD vs BID & $\begin{array}{l}2.42(1.33-4.40) \\
P=0.004 ; I^{2}=0 \%\end{array}$ \\
\hline Infections & OD vs BID & $\begin{array}{l}9.85(1.96-49.43) \\
P=0.005 ; I^{2}=83.4 \%\end{array}$ \\
\hline Diabetes & OD vs $>O D$ & $\begin{array}{l}2.24(1.38-3.66) \\
P=0.00 I ; I^{2}=0.0 \%\end{array}$ \\
\hline $\begin{array}{l}\text { Across all the } \\
\text { diseases }\end{array}$ & OD vs BID & $\begin{array}{l}4.08(1.68-9.9 \mid) \\
P=0.002 ;\left.\right|^{2}=73.4 \%\end{array}$ \\
\hline $\begin{array}{l}\text { Across all the } \\
\text { diseases }\end{array}$ & OD vs $>O D$ & $\begin{array}{l}3.50(I .73-7.08) \\
P<0.00 I ; I^{2}=69.0 \%\end{array}$ \\
\hline \multicolumn{3}{|l|}{ Persistence } \\
\hline $\begin{array}{l}\text { Cardiovascular } \\
\text { disorders }\end{array}$ & OD vs BID & $\begin{array}{l}0.85(0.65-I . I I) ; \\
P=0.235 ; I^{2}=N / A\end{array}$ \\
\hline $\begin{array}{l}\text { Across all the } \\
\text { diseases }\end{array}$ & OD vs BID & $\begin{array}{l}1.43(0.62-3.29) \\
P=0.405 ; I^{2}=96.9 \%\end{array}$ \\
\hline
\end{tabular}

Abbreviations: AIDS, acquired immunodeficiency syndrome; BID, twice daily; $\mathrm{Cl}$, confidence interval; HIV, human immunodeficiency virus; $I^{2}$, statistical heterogeneity; N/A, not applicable; OD, once daily; OR, odds ratio; TID, three times daily; vs, versus.

and one that was economic, ${ }^{54}$ provided data regarding compliance and costs associated with adherence to pain medications, respectively (Table 2). In the observational study ${ }^{53}$ patients on OD propranolol for treating migraine demonstrated higher mean compliance rates (79.8\%) than those on BID atenolol (60.0\%). Patients on BID atenolol in turn showed better compliance than TID pizotifen or TID methysergide (54.2\%); however, the differences were not substantial.

An economic evaluation using a 3-month decision model of three first-line medications for diabetic peripheral neuropathic pain by Carlos et $\mathrm{al}^{54}$ comparing duloxetine OD, pregabalin BID, and gabapentin TID demonstrated that in comparison to TID and BID, OD dosing was associated with a comparative cost savings of US\$98 and US\$129 per 
Table 4 Studies presenting data on costs associated with adherence or compliance

\begin{tabular}{|c|c|c|c|c|}
\hline Study & Disease & Type of evaluation & Results & Study conclusion \\
\hline Brown ${ }^{46}$ & Angina & $\begin{array}{l}\text { Decision-analytic } \\
\text { model }\end{array}$ & $\begin{array}{l}\text { - Estimated total NHS annual cost for } \\
\text { ISMN OD management: GB } £ 248 \\
\text { - Estimated total NHS annual cost for } \\
\text { ISMN OD management: GB } £ 250\end{array}$ & $\begin{array}{l}\text { - Fewer health service resources were consumed } \\
\text { by patients treated on OD regimen, with a higher } \\
\text { compliance rate, compared to a BID regimen }\end{array}$ \\
\hline Sidhu ${ }^{9}$ & $\begin{array}{l}\text { Renal } \\
\text { transplant }\end{array}$ & $\begin{array}{l}\text { Budget impact } \\
\text { analysis }\end{array}$ & $\begin{array}{l}\text { - Once daily tacrolimus yielded } \\
\text { cumulative cost savings of GB } £ 104,534\end{array}$ & $\begin{array}{l}\text { - Use of OD therapy could yield cost savings over } \\
4 \text { five years in comparison to BID therapy of tacrolimus }\end{array}$ \\
\hline Abecassis $^{61}$ & $\begin{array}{l}\text { Renal } \\
\text { transplant }\end{array}$ & $\begin{array}{l}\text { Cost-effectiveness } \\
\text { analysis }\end{array}$ & $\begin{array}{l}\text { - Total direct cost with OD therapy: } \\
\text { US } \$ 228,734 \\
\text { - Total direct cost with BID therapy: } \\
\text { US } \$ 238, \mid 44\end{array}$ & $\begin{array}{l}\text { - Tacrolimus OD resulted in a reduction of costs } \\
\text { relative to BID tacrolimus } \\
\text { - Tacrolimus OD was the dominant therapy in the } \\
\text { cost-effectiveness analysis }\end{array}$ \\
\hline
\end{tabular}

Note: I GBP = I.5 USD

Abbreviations: BID, twice daily; ISMN, isosorbide mononitrate nitroglycerin; OD, once daily dosing; NHS, UK National Health Service.

patient, respectively (Table 4). Incremental cost per QALY gained with OD over TID was US\$8821 (over the patients dosing lifetime).

\section{Diabetes}

Five studies presented data on adherence, compliance, or persistence to medications in type 2 diabetes. ${ }^{7,27,33,55,56}$ Random-effect meta-analysis for the assessment of compliance on data from two studies indicated OD dosing was associated with a significantly greater compliance rate compared with $>$ OD dosing (OR 2.24, 95\% CI 1.38-3.66, $P=0.001, \mathrm{I}^{2}=0.0 \%$ ) (Table 3). ${ }^{54,55}$ The remaining studies demonstrated that adherence rates varied with different assessment techniques; however, OD dosing had better adherence rates than BID/TID regimens. ${ }^{7,26,32}$

\section{HIV infection}

It was observed from six studies of antiretroviral treatments for HIV that regimens prescribed in a TID schedule were more likely to be missed compared with regimens prescribed less than TID. $8,25,35,38,57,58$

The results of random-effect meta-analysis from three studies in HIV patients indicated that the likelihood of being adherent was significantly higher with OD regimens compared with BID (OR 3.48, 95\% CI 1.32-9.17, $P=0.012$, $\left.\mathrm{I}^{2}=64.4 \%\right)$ and TID (OR 3.48, 95\% CI 1.36-8.90, $P=0.009$, $\left.\mathrm{I}^{2}=0 \%\right){ }^{24,34,37}$ However, for the BID versus TID comparison, no statistically significant difference was observed (OR 1.38, 95\% CI 0.87-2.17, $P=0.167, \mathrm{I}^{2}=0 \%$ ) (Table 3 ).

\section{Infections}

Studies of infections included patients with respiratory tract infections (RTIs), ${ }^{31,32}$ community-acquired pneumonia/acute bronchitis and streptococcal pharyngitis. ${ }^{59,60}$ Random-effect meta-analysis on data from two studies assessing compliance to antibiotic therapy among patients with RTIs demonstrated that OD dosing was nearly ten times as likely to achieve compliance relative to BID (OR 9.85, 95\% CI 1.96-49.43, $P=0.005$, $\mathrm{I}^{2}=83.4 \%$ ) (Table 3). ${ }^{31,32}$ For streptococcal pharyngitis, Raz et $\mathrm{al}^{60}$ found a significant difference in compliance rates between BID $(90 \%)$ and QID therapies $(58 \%)(P<0.001)$.

Spiritus et al ${ }^{59}$ randomized patients with lower RTI to clarithromycin BID, erythromycin QID, or cefaclor TID. The authors in this study observed that the per-patient costs of health care resource utilization were US\$191 for BID, US\$264 for QID, and US\$388 for TID (Table 4). Hospitalization costs were comparatively lower with BID (US\$28,769 for 305 patients) compared with QID (US\$73,322 for 316 patients) and TID (US\$78,734 for 289 patients). ${ }^{59}$

\section{Transplants}

Two studies assessed the economic impact of adherence to immunosuppressants among patients undergoing kidney transplantation, ${ }^{9,61}$ and one observational study evaluated compliance with interventions for liver transplantation. ${ }^{62}$ Abecassis et a ${ }^{61}$ modeled patient outcomes and treatment costs over 5 years for renal transplant comparing BID with OD tacrolimus (Table 4). Fewer patients were adherent to BID compared with OD immunosuppressants. Use of OD tacrolimus resulted in a reduction in 5 -year discounted average patient total treatment costs relative to BID tacrolimus (US\$228,734 versus US $\$ 238,144) .{ }^{61}$ Similarly, Sidhu et al ${ }^{9}$ calculated a $74 \%$ probability of adherence with OD versus $55 \%$ with BID tacrolimus (Table 4 ). Over 5 years, the OD regimen yielded cumulative cost savings relative to BID of $£ 104,534$, including savings in drug acquisition $(£ 69,180)$, management of acute rejection episodes ( $£ 22,837)$, retransplantation (£417), and dialysis (£13,631). ${ }^{9}$ Further, Eberlin and $\mathrm{Kramer}^{62}$ demonstrated that switching patients from BID to OD tacrolimus-based regimen for liver transplantation resulted in a trend towards better compliance with OD regimen. 


\section{Ulcerative colitis}

Three studies examined different dosing schedules of treatments for ulcerative colitis with adherence and persistence to medications, ${ }^{26,28,63}$ and another study presented data on the associated economic impact (Table 2). ${ }^{64}$ Random-effect meta-analysis on treatment adherence for ulcerative colitis indicated that OD dosing was associated with better adherence compared with $>$ OD dosing (OR $3.20,95 \%$ CI $\left.0.78-13.14, P=0.107, \mathrm{I}^{2}=39.4 \%\right){ }^{25,27}$ Lachaine et $\mathrm{ll}^{63}$ reported that adherence and persistence to mesalazine formulations were relatively poor; however, improved adherence and persistence were observed with OD dosing.

Connolly et $\mathrm{al}^{64}$ conducted an economic evaluation comparing OD with BID mesalazine based on results from an RCT (Table 4). Average annual costs per person treated with OD or BID mesalazine, including costs of treatment failure were $£ 815$ and $£ 971$, respectively, with an annual costsavings (incremental cost per year) of $£ 156$ when using an OD regimen. OD had $>0.95$ probability of being cost-effective compared with BID based on accepted willingness to pay thresholds applied by the UK National Health Service. ${ }^{64}$

\section{Discussion}

Drug regimen complexity, ie, taking multiple daily doses of an intervention, is a critical factor affecting medication-taking behavior. The current analysis demonstrated that reducing the dosing regimen complexity improves adherence, compliance, and/or persistence. Across a variety of studied conditions, OD dosing of oral medications was associated with higher adherence compared with multiple-dosing schedules, which in turn may have led to decreased health care costs.

Our results are consistent with those found in empirical studies and literature reviews, including published metaanalyses, that showed adherence is inversely proportional to the number of medication doses per day. $15,16,18-20,65,66$ A systematic review of 76 studies (1986-2000) by Claxton et $\mathrm{al}^{16}$ to measure compliance found that simpler, less frequent dosing regimens resulted in better compliance across a variety of therapeutic classes. A review by Shi et a ${ }^{15}$ of the effect of dose frequency on compliance between 1966 and 2006 showed that reducing dose frequency via new dosage forms and formulations may improve medication compliance. Similarly, the recent meta-analysis by Coleman et $\mathrm{al}^{20}$ that included studies up to December 2011 found mean weighted adherence rates that were progressively lower as dosing frequency increased. The results of our quantitative analysis were also consistent with findings reported by other meta-analyses conducted specifically in the disease areas of hypertension and HIV infection. ${ }^{18,19}$

Economic evidence associated with adherence was reported in a variable manner; therefore, quantitative analyses were not possible. However, descriptive evaluation of the available evidence suggested less consumption of medical resources with OD dosing compared with BID dosing. More research is needed to quantify the extent and precision of the magnitude of effect.

This analysis could potentially be criticized for analyzing compliance and adherence seperately. However, our analysis was based on the terms used in the original studies, since ISPOR definitions consider these two terms to be synonymous. ${ }^{12}$ In this regard, it should be noted that, although ISPOR definitions consider these two terms to be synonymous, differences have been noted in how these terms are used. Within the published literature, adherence has also been defined as a health plan constructed and agreed to by the patient in partnership with a health care provider in clinical decision making, while compliance implies a oneway relationship; the clinician dictates the medical regimen, and the patient is expected to comply ${ }^{67}$ A related limitation of this review is that the studies largely reported adherence based on patient self-report, rather than objective measures such as blood level monitoring, prescription refills, and electronic monitoring, making the studies subject to patient recall bias. ${ }^{68}$ Nevertheless, despite these two limitations, there was general concordance of results between compliance and adherence in our analysis.

A meta-analysis can generate inherent biases when combining data from different studies with variable sample sizes, study designs, and outcome definitions. In our meta-analysis, all variables that could affect adherence, other than daily dose frequency, were assumed to be equal among comparators, which may not hold true in real-world settings. Data were combined from studies that used various definitions of adherence, compliance, and persistence, which is another limitation of this review. In addition, as persistence is a time-related event, studies assessing persistence used different methodologies and time points to assess this outcome. This difference was also reflected by the high heterogeneity associated with the meta-analysis results of overall persistence. However, random effects meta-analysis was employed to take into account heterogeneity due to potential confounding factors. Further, sensitivity analysis with respect to study designs to explore the impact of heterogeneity on the results revealed that higher adherence, compliance, and persistence were observed with OD versus $>$ OD. 
These results were consistent with the findings of other random-effects meta-analyses.

It should also be noted that some studies utilized different medications for the different dosing regimens. Thus, it is possible that there may have been factors other than the dosing frequency that may have contributed to the observed patterns of adherence/compliance, such as side-effects, size of tablet or capsule, taste, timing of administration (morning or evening, with or without food). While this may also represent a limitation of the current study, to our knowledge, factors that may relate to patient preference of medications and their impact on adherence, are rarely included in published studies and difficult to account for in such meta-analyses.

Knowing that poor treatment adherence/compliance/ persistence is a problem in chronic pain patients, we found only two published studies addressing the relationship of adherence to treatment regimens in this population. Additional research is required to better characterize the nature and correlates of nonadherence (or noncompliance or nonpersistence) in patients being treated for chronic pain conditions. This lack of data also highlights the need for correlating adherence with economic outcomes in chronic pain. Although such a correlation was assessed in several other conditions, the overall paucity of studies investigating the impact of adherence on health care resource utilization and costs suggests that this represents an important research gap. An additional need is more detailed analysis of the relationship between dosing frequency and clinical outcomes.

Despite these limitations, there are several strengths to this review. The methodology involved was rigorous and followed stringent PRISMA guidelines. The effect of pooling different study designs and analysis types for examining overall adherence rates across different dosing schedules showed no evidence of bias in the results. The quantitative and descriptive evidence both indicated that the limitations considered did not change the overall observation that a reduction in dosing frequency resulted in better adherence, which may have contributed to a reduction in health care costs. Finally, our analysis was not limited to RCTs; rather, it included all published study designs.

\section{Conclusion}

Access to simplified dosage regimens by patients may be an important aspect in maximizing therapeutic success. The current meta-analysis suggested that the prescribed number of doses per day was inversely proportional to adherence/compliance/persistence across all acute and chronic conditions evaluated. In turn, poor adherence to medication regimens may result in greater consumption of medical resources, which in turn may lead to increased health care costs. Clinicians should be aware that medication adherence is a complex phenomenon with several factors at play and efforts to improve adherence should not be restricted to prescription of OD medications. ${ }^{69,70}$ Other factors, including potency, tolerability, and risk of resistance to medications, in addition to patient's individual adherence patterns, are important considerations when selecting the optimal course of therapy for patients.

\section{Disclosure}

This research was supported by Pfizer Inc. Alesia Sadosky and Joseph C Cappelleri are paid employees of Pfizer Inc. Kunal Srivastava, Anamika Arora, and Aditi Kataria are employees of Heron Health who were paid consultants to Pfizer Inc in the development and execution of this study and publication related deliverables. Andrew M Peterson was not financially compensated for his collaboration on this project including publication related activities.

\section{References}

1. World Health Organization. Failure to take prescribed medicine for chronic diseases is a massive, world-wide problem [news release]. Available from: http://www.who.int/mediacentre/news/releases/2003/ pr54/en. Accessed February 12, 2013.

2. Jackevicius CA, Mamdani M, Tu JV. Adherence with statin therapy in elderly patients with and without acute coronary syndromes. JAMA. 2002;288(4):462-467.

3. Dunbar-Jacob J, Erlen JA, Schlenk EA, Ryan CM, Sereika SM, Doswell WM. Adherence in chronic disease. Annu Rev Nurs Res. 2000;18:48-90.

4. Stuart B, Briesacher B. Medication decisions - right and wrong. Med Care Res Rev. 2002;59(2):123-145.

5. Kyngas H, Lahdenpera T. Compliance of patients with hypertension and associated factors. J Adv Nurs. 1999;29(4):832-839.

6. Stang P, Suppapanaya N, Hogue SL, Park D, Rigney U. Persistence with once-daily versus twice-daily bupropion for the treatment of depression in a large managed-care population. Am J Ther. 2007;14(3):241-246.

7. Dezii CM, Kawabata H, Tran M. Effects of once-daily and twice-daily dosing on adherence with prescribed glipizide oral therapy for type 2 diabetes. South Med J. 2002;95(1):68-71.

8. Carrieri MP, Leport C, Protopopescu C, et al. Factors associated with nonadherence to highly active antiretroviral therapy: a 5-year follow-up analysis with correction for the bias induced by missing data in the treatment maintenance phase. J Acquir Immune Defic Syndr. 2006; 41(4):477-485.

9. Sidhu M, Lees L, Warner J. Five-year budget impact analysis of oncedaily versus twice-daily tacrolimus, in patients undergoing renal transplant in the United Kingdom [abstract]. Value Health. 2010;13:A170.

10. Song X, Sander S, Varker H, Amin A. Patterns and predictors of persistence of warfarin and other commonly-utilized chronic medications among patients with atrial fibrillation [abstract]. Value Health. 2010; 13:A170.

11. DiMatteo MR. Variations in patients' adherence to medical recommendations: a quantitative review of 50 years of research. Med Care. 2004;42(3):200-209. 
12. Cramer JA, Roy A, Burrell A, et al. Medication compliance and persistence: terminology and definitions. Value Health. 2008;11(1):44-47.

13. Arnsten JH, Gelfand JM, Singer DE. Determinants of compliance with anticoagulation: a case-control study. Am J Med. 1997;103(1):11-17.

14. Osterberg L, Blaschke T. Adherence to medication. $N$ Engl J Med 2005;353(5):487-497.

15. Shi L, Hodges M, Yurgin N, Boye KS. Impact of dose frequency on compliance and health outcomes: a literature review (1966-2006). Expert Rev Pharmacoecon Outcomes Res. 2007;7(2):187-202.

16. Claxton AJ, Cramer J, Pierce C. A systematic review of the associations between dose regimens and medication compliance. Clin Ther. 2001; 23(8):1296-1310.

17. Richter A, Anton SE, Koch P, Dennett SL. The impact of reducing dose frequency on health outcomes. Clin Ther. 2003;25(8):2307-2335; discussion 2306

18. Iskedjian M, Einarson TR, MacKeigan LD, et al. Relationship between daily dose frequency and adherence to antihypertensive pharmacotherapy: evidence from a meta-analysis. Clin Ther. 2002; 24(2):302-316.

19. Parienti JJ, Bangsberg DR, Verdon R, Gardner EM. Better adherence with once-daily antiretroviral regimens: a meta-analysis. Clin Infect Dis. 2009;48(4):484-488.

20. Coleman CI, Limone B, Sobieraj DM, et al. Dosing frequency and medication adherence in chronic disease. J Manag Care Pharm. 2012;18(7): 527-539.

21. Moher D, Liberati A, Tetzlaff J, Altman DG. Preferred reporting items for systematic reviews and meta-analyses: the PRISMA statement. Ann Intern Med. 2009;151(4):264-269, W264.

22. DerSimonian R, Laird N. Meta-analysis in clinical trials. Control Clin Trials. 1986;7(3):177-188.

23. Higgins JP, Thompson SG, Deeks JJ, Altman DG. Measuring inconsistency in meta-analyses. BMJ. 2003;327(7414):557-560.

24. Berlin JA, Antman EM. Advantages and limitations of metaanalytic regressions of clinical trials data. Online J Curr Clin Trials. June 4, 1994;Doc No 134.

25. Negredo E, Molto J, Munoz-Moreno JA, et al. Safety and efficacy of once-daily didanosine, tenofovir and nevirapine as a simplification antiretroviral approach. Antivir Ther. 2004;9(3):335-342.

26. Kane S, Huo D, Magnanti K. A pilot feasibility study of once daily versus conventional dosing mesalamine for maintenance of ulcerative colitis. Clin Gastroenterol Hepatol. 2003;1(3):170-173.

27. Winkler A, Teuscher AU, Mueller B, Diem P. Monotoring adherence to prescribed medication in type 2 diabetic patients treated with sulfonylureas. Swiss Med Wkly. 2002;132(27-28):379-385.

28. Hawthorne AB, Stenson R, Gillespie D, et al. Once daily mesalazine as maintenance therapy for ulcerative colitis (UC): a one-year single-blind randomized trial [abstract]. Gastroenterology. 2011; 140(Suppl):S65.

29. Baird MG, Bentley-Taylor MM, Carruthers SG, et al. A study of efficacy, tolerance and compliance of once-daily versus twice-daily metoprolol (Betaloc) in hypertension. Betaloc Compliance Canadian Cooperative Study Group. Clin Invest Med. 1984;7(2):95-102.

30. Andrejak M, Genes N, Vaur L, Poncelet P, Clerson P, Carre A. Electronic pill-boxes in the evaluation of antihypertensive treatment compliance: comparison of once daily versus twice daily regimen. $\mathrm{Am}$ J Hypertens. 2000;13(2):184-190.

31. Kardas P. Once-daily dosage secures better compliance with antibiotic therapy of respiratory tract infections than twice daily dosage. $\mathrm{J} \mathrm{Appl}$ Res. 2003;3(2):201-206.

32. Kardas P. Comparison of patient compliance with once-daily and twice-daily antibiotic regimens in respiratory tract infections: results of a randomized trial. J Antimicrob Chemother. 2007;59(3): 531-536.

33. Pullar T, Birtwell AJ, Wiles PG, Hay A, Feely MP. Use of a pharmacologic indicator to compare compliance with tablets prescribed to be taken once, twice, or three times daily. Clin Pharmacol Ther. 1988;44(5):540-545.
34. Maro EE, Lwakatare J. Medication compliance among Tanzanian hypertensives. East Afr Med J. 1997;74(9):539-542.

35. Echarri Martinez LE, Rodriguez Gonzalez CG, Castillo Romera I, et al. Evolution of adherence to antiretroviral treatment in a Spanish hospital during 2001, 2005, and 2008. Lat Am J Pharm. 2011;30:1173-1178.

36. McLaughlin T, Hogue SL, Stang PE. Once-daily bupropion associated with improved patient adherence compared with twice-daily bupropion in treatment of depression. Am J Ther. 2007;14(2):221-225.

37. Hess G, Bhandary D, Fonseca E, et al. Adherence to medications with once-a-day (qd) and twice-a-day (bid) dosing formulations in acute coronary syndrome (ACS) patients [abstract]. Value Health. 2011; 14:A44.

38. Moyle G. The Assessing Patients' Preferred Treatments (APPT-1) study. Int J STD AIDS. 2003;14 Supp1 1:34-36.

39. Granger AL, Fehnel SE, Hogue SL, Bennett L, Edin HM. An assessment of patient preference and adherence to treatment with Wellbutrin SR: a web-based survey. J Affect Disord. 2006;90(2-3):217-221.

40. Turki AK, Sulaiman SAS. Adherence to antihypertensive therapy in general hospital of Penang: does daily dose frequency matter? Jordan J Pharm Sci. 2009;2:167-175.

41. Begg CB, Mazumdar M. Operating characteristics of a rank correlation test for publication bias. Biometrics. 1994;50(4):1088-1101.

42. Egger M, Davey Smith G, Schneider M, Minder C. Bias in metaanalysis detected by a simple, graphical test. BMJ. 1997;315(7109): 629-634.

43. Celis H, Staessen J, Fagard R, Thijs L, Amery A. Does isradipine modified release $5 \mathrm{mg}$ once daily reduce blood pressure for 24 hours? J Cardiovasc Pharmacol. 1993;22(2):300-304.

44. Girvin B, McDermott BJ, Johnston GD. A comparison of enalapril $20 \mathrm{mg}$ once daily versus $10 \mathrm{mg}$ twice daily in terms of blood pressure lowering and patient compliance. J Hypertens. 1999;17(11):1627-1631.

45. Boissel JP, Meillard O, Perrin-Fayolle E, et al. Comparison between a bid and a tid regimen: improved compliance with no improved antihypertensive effect. The EOL Research Group. Eur J Clin Pharmacol. 1996;50(1-2):63-67.

46. Brown RE, Kendall MJ, Halpern MT. Cost analysis of once-daily ISMN versus twice-daily ISMN or transdermal patch for nitrate prophylaxis. J Clin Pharm Ther. 1997;22(1):67-76.

47. Kardas P. Compliance, clinical outcome, and quality of life of patients with stable angina pectoris receiving once-daily betaxolol versus twice daily metoprolol: a randomized controlled trial. Vasc Health Risk Manag. 2007;3(2):235-242.

48. Doesch AO, Mueller S, Konstandin $\mathrm{M}$, et al. Increased adherence after switch from twice daily calcineurin inhibitor based treatment to once daily modified released tacrolimus in heart transplantation: a pre-experimental study. Transplant Proc. 2010;42(10): 4238-4242.

49. Bae JP, Anderson J, Zagar A, et al. The effects of dosing complexity on adherence with prescription medications commonly used for cardiovascular patients [abstract]. Value Health. 2010:A360.

50. Stang P, Young S, Hogue S. Better patient persistence with oncedaily bupropion compared with twice-daily bupropion. Am J Ther. 2007;14(1):20-24.

51. Cramer JA, Mattson RH, Prevey ML, Scheyer RD, Ouellette VL. How often is medication taken as prescribed? A novel assessment technique. JAMA. 1989;261(22):3273-3277.

52. Pfeiffer PN, Ganoczy D, Valenstein M. Dosing frequency and adherence to antipsychotic medications. Psychiatr Serv. 2008;59(10):1207-1210.

53. Mulleners WM, Whitmarsh TE, Steiner TJ. Noncompliance may render migraine prophylaxis useless, but once-daily regimens are better. Cephalalgia. 1998;18(1):52-56.

54. Carlos F, Ramirez J, Galindo-Suarez RM, Duenas H. PDB33 Economic evaluation of three first-line medications in painful diabetic peripheral neuropathy in Mexico. Value in Health. 2010;13(3):A60.

55. Kardas P. The DIACOM study (effect of DosIng frequency of oral Antidiabetic agents on the COMpliance and biochemical control of type 2 diabetes). Diabetes Obes Metab. 2005;7(6):722-728. 
56. Charpentier G, Fleury F, Dubroca I, Vaur L, Clerson P. Electronic pill-boxes in the evaluation of oral hypoglycemic agent compliance. Diabetes Metab. 2005;31(2):189-195.

57. Stone VE, Hogan JW, Schuman P, et al. Antiretroviral regimen complexity, self-reported adherence, and HIV patients' understanding of their regimens: survey of women in the her study. $J$ Acquir Immune Defic Syndr. 2001;28(2):124-131.

58. Abellan J, Garrote M, Pulido F, Rubio R, Costa JR. Evaluation of adherence to a triple antiretroviral therapy in HIV-positive patients. Eur J Intern Med. 1999;10(4):202-205.

59. Spiritus EM, Chang RJ, Zhang JX, et al. Cost savings of clarithromycin compared with erythromycin or cefaclor in the treatment of lower respiratory tract infection: Results of a randomized, multicenter study. Am J Manag Care. 1998;4 Suppl 11:S562-S570.

60. Raz R, Elchanan G, Colodner R, et al. Penicillin V twice daily vs four times daily in the treatment of streptococcal pharyngitis. Infect Dis Clin Pract. 1995;4(1):50-54.

61. Abecassis MM, Seifeldin R, Riordan ME. Patient outcomes and economics of once-daily tacrolimus in renal transplant patients: results of a modeling analysis. Transplant Proc. 2008;40(5):1443-1445.

62. Eberlin MB, Kramer I. Evaluation of medication compliance of liver transplant patients switched from a twice-daily to a once-daily tacrolimus-based regimen [abstract]. Pharm World Sci. 2010;32:670-671.

63. Lachaine J, Beauchemin C, Yen L, Hodgkins P. Medication adherence and persistence in the treatment of ulcerative colitis analyses with the RAMQ database [abstract]. Can J Gastroenterol. 2011;25(Suppl A): Abstract A072.
64. Connolly MP, Nielsen SK, Currie CJ, Poole CD, Travis SP. An economic evaluation comparing once daily with twice daily mesalazine for maintaining remission based on results from a randomised controlled clinical trial. J Crohns Colitis. 2009;3(1):32-37.

65. Fischer RG. Compliance-oriented prescribing: simplifying drug regimens. J Fam Pract. 1980;10(3):427-435.

66. Bae JP, Dobesh PP, Klepser DG, et al. Adherence and dosing frequency of common medications for cardiovascular patients. Am JManag Care. 2012;18(3):139-146.

67. Gould E, Mitty E. Medication adherence is a partnership, medication compliance is not. Geriatr Nurs. 2010;31(4):290-298.

68. Urquhart J. Ascertaining how much compliance is enough with outpatient antibiotic regimens. Postgrad Med J. 1992;68 Suppl 3: S49-S58; discussion S59.

69. Petersen ML, Wang Y, van der Laan MJ, Guzman D, Riley E, Bangsberg DR. Pillbox organizers are associated with improved adherence to HIV antiretroviral therapy and viral suppression: a marginal structural model analysis. Clin Infect Dis. 2007;45(7):908-915.

70. Simoni JM, Pearson CR, Pantalone DW, Marks G, Crepaz N. Efficacy of interventions in improving highly active antiretroviral therapy adherence and HIV-1 RNA viral load. A meta-analytic review of randomized controlled trials. J Acquir Immune Defic Syndr. 2006; 43 Suppl 1:S23-S35. 


\section{Appendix}

Appendix Study protocol listing the eligibility criteria for inclusion/exclusion of studies in the review as per the PRISMA guidelines

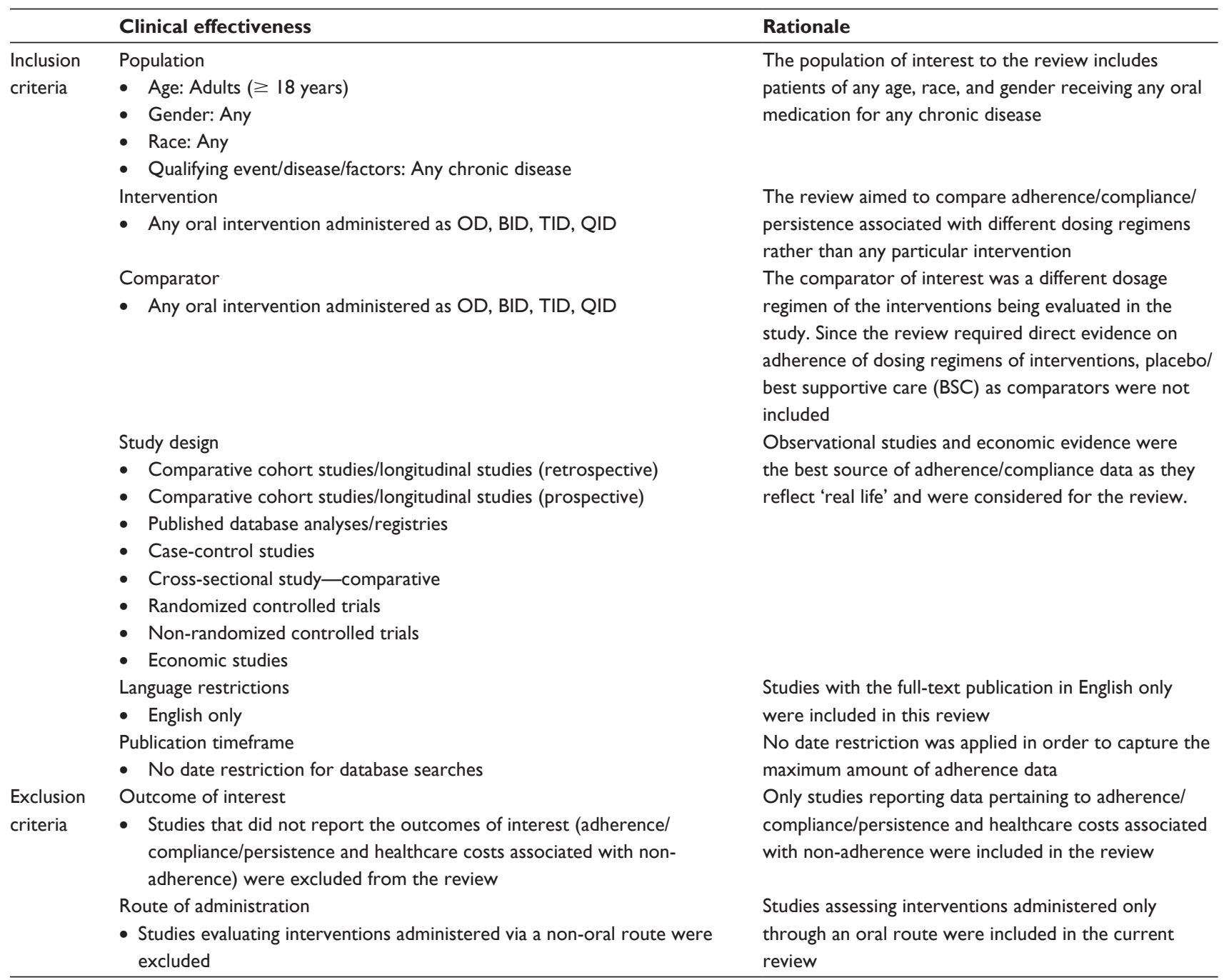

Abbreviations: BID, twice daily; BSC, best supportive care; OD, once daily; QID, four times daily; TID, three times daily. 


\section{Publish your work in this journal}

Patient Preference and Adherence is an international, peer-reviewed, open access journal focusing on the growing importance of patient preference and adherence throughout the therapeutic continuum. Patient satisfaction, acceptability, quality of life, compliance, persistence and their role in developing new therapeutic modalities and compounds to

optimize clinical outcomes for existing disease states are major areas of interest. This journal has been accepted for indexing on PubMed Central. The manuscript management system is completely online and includes a very quick and fair peer-review system. Visit http://www.dovepress.com/ testimonials.php to read real quotes from published authors.

Submit your manuscript here: http://www.dovepress.com/patient-preference-and-adherence-journal 